\title{
Effect of Heat Drawing Process on Mechanical Properties of Dry-Jet Wet Spun Fiber of Linear Low Density Polyethylene/Carbon Nanotube Composites
}

\author{
Jong Won Kim and Joon Seok Lee \\ Department of Textile Engineering and Technology, Yeungnam University, Gyeongsan 38541, Republic of Korea \\ Correspondence should be addressed to Joon Seok Lee; leejs@ynu.ac.kr
}

Received 10 February 2017; Revised 9 August 2017; Accepted 27 August 2017; Published 3 October 2017

Academic Editor: Peng He

Copyright (C) 2017 Jong Won Kim and Joon Seok Lee. This is an open access article distributed under the Creative Commons Attribution License, which permits unrestricted use, distribution, and reproduction in any medium, provided the original work is properly cited.

\begin{abstract}
Polyethylene is one of the most commonly used polymer materials. Even though linear low density polyethylene (LLDPE) has better mechanical properties than other kinds of polyethylene, it is not used as a textile material because of its plastic behavior that is easy to break at the die during melt spinning. In this study, LLDPE fibers were successfully produced with a new approach using a dry-jet wet spinning and a heat drawing process. The fibers were filled with carbon nanotubes (CNTs) to improve the strength and reduce plastic deformation. The crystallinity, degree of orientation, mechanical properties (strength to yield, strength to break, elongation at break, and initial modulus), electrical conductivity, and thermal properties of LLDPE fibers were studied. The results show that the addition of CNTs improved the tensile strength and the degree of crystallinity. The heat drawing process resulted in a significant increase in the tensile strength and the orientation of the CNTs and polymer chains. In addition, this study demonstrates that the heat drawing process effectively decreases the plastic deformation of LLDPE.
\end{abstract}

\section{Introduction}

Polyethylene (PE) is one of the most widely used thermoplastic materials because of its high toughness, near-zero moisture absorption, excellent chemical inertness, low coefficient of friction, ease of processing, and low electrical conductivity. The mechanical properties of PE are impacted by the extent and type of branching, the crystal structure, and the molecular weight [1]. PE polymers are classified into several different categories, but mostly these do not depend on the density or branching. The main forms of PE are high density polyethylene (HDPE), high molecular weight HDPE (HMWHDPE), ultrahigh molecular weight polyethylene (UHMWPE), linear low density polyethylene (LLDPE), and very low density polyethylene (VLDPE). These categories are then subdivided into groups related to the density and branching. In general, the most used PE grades are HDPE, LDPE, and mediumdensity polyethylene (MDPE) [2]. LDPE is considered as one of the commercially important thermoplastics. In particular, it is used for a wide range of applications that require low density, good processability, and easy molding.

LLDPE has better tensile strength, heat tolerance, and low-temperature properties than LDPE. It also has better environmental stress cracking resistance and impact strength and less intensity difference in various directions than HDPE. Although it has suitable properties for use as a textile material, to date, LLDPE has only been used for laminate and multilayer films and for injection molding (in HDPE/LDPE blends) [3, 4]. Some companies developed spinnable LLDPE for textile application, but it is a blend of PE and other additive polymers. Therefore, LLDPE was made as staple fiber form which was used in nonwoven fiber $[5,6]$ and bonding fiber $[7,8]$. However, it has never been manufactured as thin fiber before [9]. In order to manufacture thin LLDPE fibers, high-speed winding is necessary during the spinning process, but the fibers are easily broken during the spinning process due to the plastic behavior of LLDPE. In some studies, to prevent the breakage of LLDPE fibers, a heat drawing 
process was applied after winding without any tension in the melt spinning process. Although the LLDPE fibers have been made, the draw ratio of the fibers was very low so only thick fibers with the diameter of few hundred microns were produced, which could not be used in most textile applications $[10,11]$. In addition, for use as a precursor for the production of carbon fibers, the diameter of the LLDPE fibers should be several tens of microns or less [12].

New composites with PE as the matrix are used in many applications and have better mechanical and physical properties than the pure polymer alone. PE composites can be used in packaging, electrical, thermal energy storage, automotive, biomedical, and space applications [13-17]. Although PE is a relatively soft material, it has broad applications due to its resistance to moisture, corrosion, wear, and chemicals and an extremely low cost. PE composites with clay and multiwalled carbon nanotubes have been fabricated to improve the toughness, tensile strength, and other chemical, thermal, and barrier properties $[18,19]$. Because of high Young's modulus of 1-5 TPa and anisotropic properties, CNTs have been proposed as a material that can increase the elastic modulus and tensile strength of composite materials [20, 21]. In addition, $\mathrm{PE}$ has been used as a matrix for preparing composites with CNTs using UHMWPE [22-25], HDPE [26, 27], and LDPE $[19,28]$ and as a thin film [29-31].

In this study, to apply LLDPE on the textile application, thin LLDPE fiber was manufactured by dry-jet wet spinning. After manufacturing, heat drawing process was applied. Then manufactured LLDPE fiber analyzed the degree of crystallinity, the degree of orientation, the mechanical properties (strength to yield, strength to break, elongation at break, and initial modulus), electrical conductivity, and thermal properties.

\section{Materials and Methods}

2.1. Materials. LLDPE (LLDPE-3126, melt flow index $=1 \mathrm{~g} /$ $10 \mathrm{~min}, \mathrm{Mw} / \mathrm{Mn}=127,028 / 35,091$, Hanwha Chemical Co., Seoul, Korea) was used as the polymer matrix and decahydronaphthalene (Decalin, $\mathrm{C}_{10} \mathrm{H}_{18}, \mathrm{Mw}=138.25$, Kanto Chemical Co., Seoul, Korea) was used as solvent. Multiwalled carbon nanotubes (MWCNT, aspect ratio around 500, Carbon Nanotech Co., Pohang, Korea) were used as the filler.

2.2. Preparation of LLDPE Fiber. The mixture of $80 \mathrm{wt} . \%$ decalin and $20 \mathrm{wt} . \%$ LLDPE was spun into fibers in distilled water (air gap: $10 \mathrm{~mm}$ ) at room temperature through a spinneret die. A dry-jet wet spinning machine (KNFI-1000, Koen Co., Ansan, Korea) was maintained at $170^{\circ} \mathrm{C}$. The die consisted of spinneret hole with a diameter of $250 \mu \mathrm{m}$, at a spinneret pressure of $2 \mathrm{kgf} / \mathrm{cm}^{2}$ and take-up speed of $15.07 \mathrm{~m} / \mathrm{min}$. After $24 \mathrm{~h}$ dipping in $\mathrm{n}$-hexane $\left(\mathrm{C}_{6} \mathrm{H}_{14}\right.$, Duksan Co., Ansan, Korea) to elute the decalin, in the fiber, the LLDPE fiber was rinsed three times with distilled water. The LLDPE fiber was drawn at $80^{\circ} \mathrm{C}$ with a draw ratio of 4 using a batch type hot draw machine (UL-FD300, UL Sic Co., Daegu, Korea) and then cooled down gradually. The diameter of LLDPE fiber was calculated on the basis of density $\left(\rho=0.921 \mathrm{~g} / \mathrm{cm}^{3}\right)$ and constant length system $(1$ Denier $=1 \mathrm{~g} / 9000 \mathrm{~m})$. The diameter of undrawn fibers and drawn fibers was approximately $63 \mu \mathrm{m}$ and $32 \mu \mathrm{m}$ for each. The composite LLDPE fibers were prepared by decalin with MWCNT dispersed by ultrasonication. The spinning method is the same as that of neat-LLDPE. The content of MWCNT was controlled by the amount of neatdecalin and decalin dispersed with MWCNT. Finally, the content of MWCNT in the composite LLDPE fibers ranged from $0 \mathrm{wt} . \%$ to $2 \mathrm{wt} . \%$.

2.3. Characterization. To investigate the crystallinity of the LLDPE fiber as a function of MWCNT content and draw ratio, X-ray diffraction (XRD) was undertaken using a MPD diffractometer (PANalytical, Eindhoven, Netherlands). Differential scanning calorimetry (DSC, Q-200, TA Instruments, DW, USA) patterns of the LLDPE fibers were monitored between 50 and $200^{\circ} \mathrm{C}$ at a heating rate of $10^{\circ} \mathrm{C} / \mathrm{min}$ in a nitrogen atmosphere. The degree of crystallinity $\left(X_{c}\right)$ was determined from

$$
X_{c}=\frac{\Delta H_{m}}{\Delta H^{\circ}{ }_{m}} \times \frac{100}{w},
$$

where $\Delta H_{m}$ is the melting enthalpy calculated from the experimental data and $\Delta H^{\circ}{ }_{m}$ is the enthalpy of fusion of $100 \%$ crystalline PE $\left(\Delta H_{m}^{\circ}=290 \mathrm{~J} / \mathrm{g}\right)$ and $w$ is the weight fraction of LLDPE in the composite fiber [31,32].

The degree of orientation was measured from the parallel and perpendicular axes using a polarizing microscope (AXSZ-400B, Axis Co., Minbo, China). The birefringence $\left(\Delta_{n}\right)$ was calculated from the measured refractive index using

$$
\Delta_{n}=n_{\|}-n_{\perp}
$$

where $n_{\|}$is the refractive index in the parallel direction and $n_{\perp}$ is the refractive index in the perpendicular direction.

The tensile properties were measured on five different specimens with a length of $100 \mathrm{~mm}$, holding the end of specimen with silicone grip at a cross head speed of $300 \mathrm{~mm} / \mathrm{min}$, using a tensile tester (OTT-05, Oriental Co., Seoul, Korea) with a $3 \mathrm{~N}$ load cell. Both ends of the fiber, $10 \mathrm{~cm}$ in length, were coated with a silver paste and the electrical resistivity was measured using an electrical resistivity meter (MI2077, Metrel Co., Horjul, Slovenia) to calculate the electrical conductivity $(\sigma)$ according to

$$
\sigma(\mathrm{S} / \mathrm{cm})=\frac{d}{(A \times R)},
$$

where $d$ is the distance between the electrodes $(\mathrm{cm}), A$ is the cross-sectional area of the fiber $\left(\mathrm{cm}^{2}\right)$, and $R$ is the electrical resistivity $(\Omega)$.

The cross-sections of the LLDPE fibers were observed by scanning electron microscopy (SEM, S-4100, Hitachi, Tokyo, Japan). Before SEM observation, specimens were mounted with aluminum plate and then sputter coated with platinum. Specimens were observed at an accelerating voltage of $10 \mathrm{kV}$.

\section{Results and Discussion}

3.1. XRD and DSC. Figure 1 shows XRD patterns of LLDPE as a function of CNT content. Figure 1(a) shows undrawn 


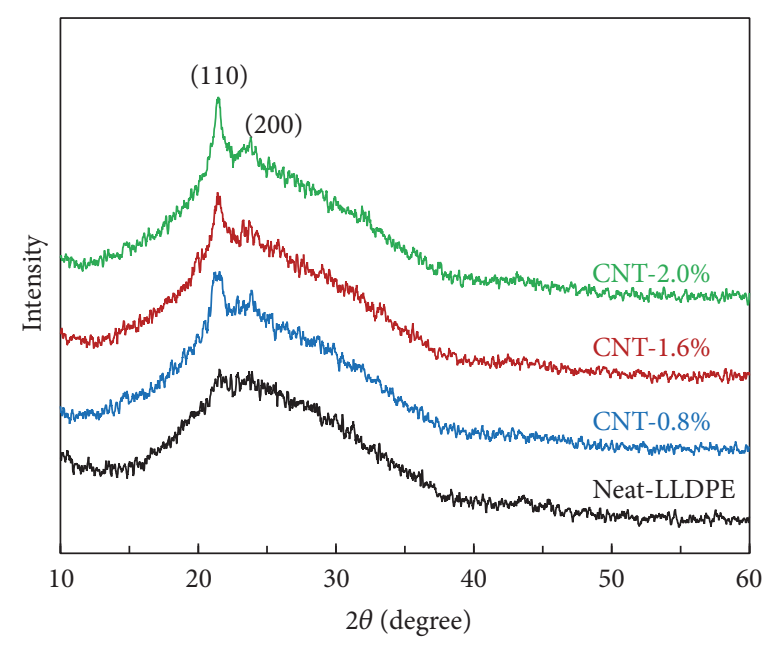

(a)

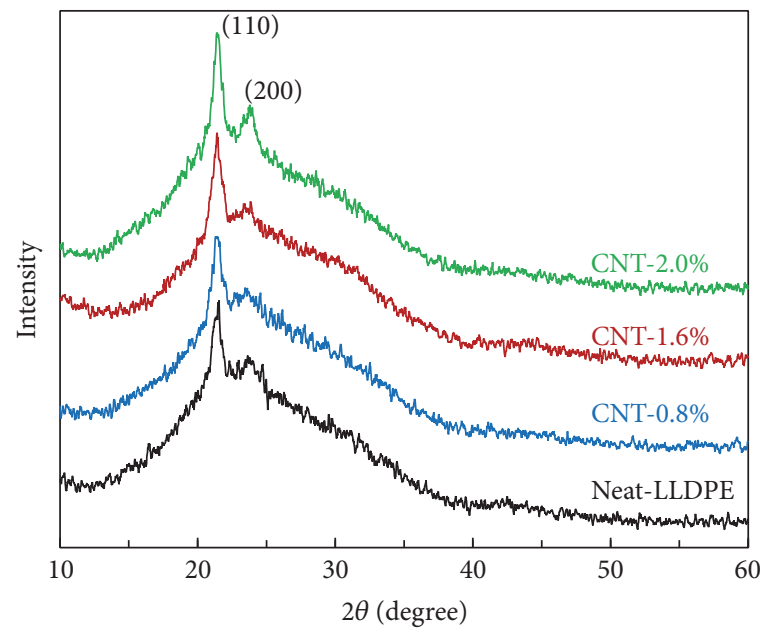

(b)

FIGURE 1: X-ray diffraction patterns of LLDPE fiber as a function of CNTs content: (a) undrawn LLDPE fiber; (b) heat drawn LLDPE fiber (DR 4).

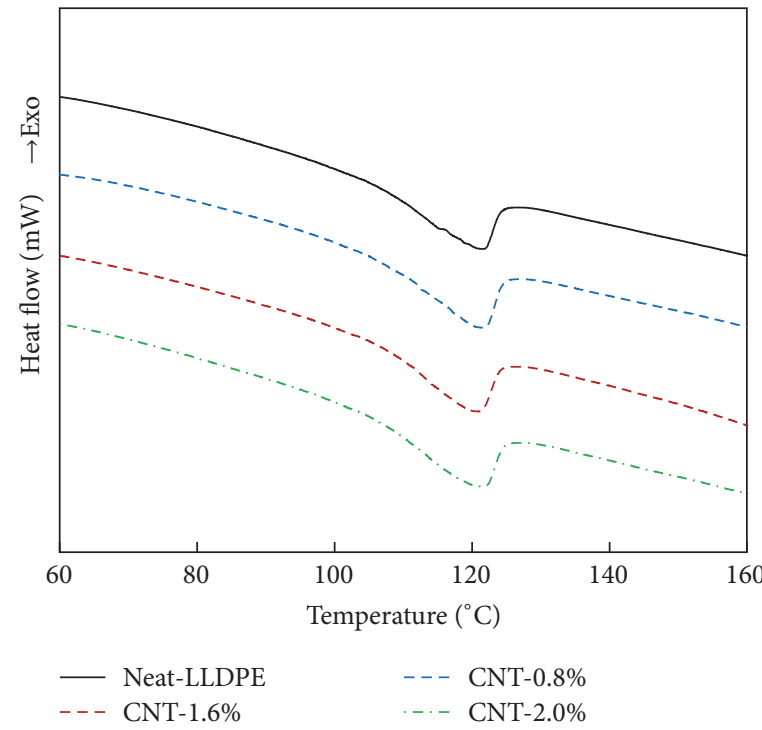

(a)

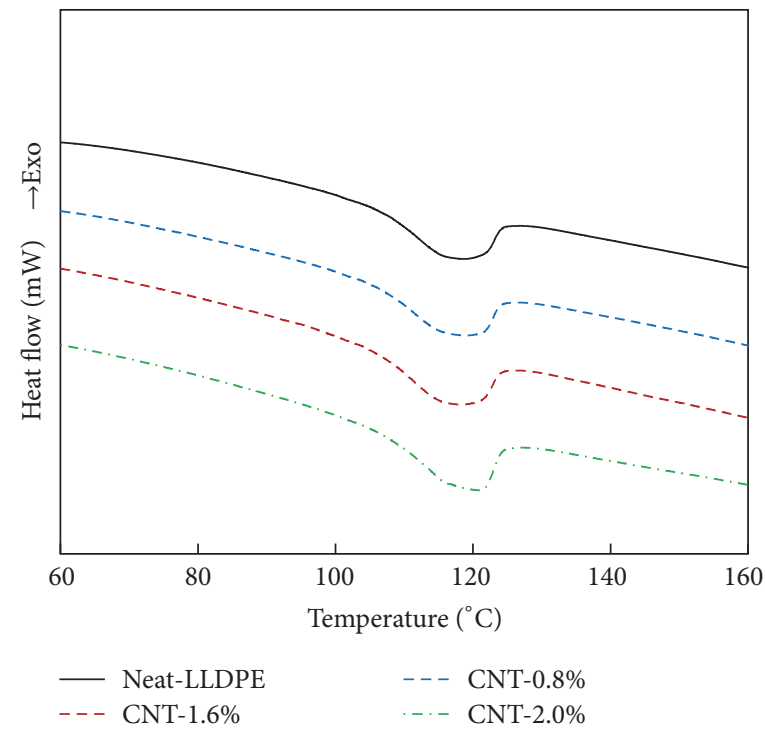

(b)

FIgURE 2: DSC patterns as a function of CNTs content: (a) undrawn and (b) heat drawn LLDPE fibers with a draw rate of 4.

LLDPE fiber. The XRD peaks at $21.6^{\circ}$ and $24.0^{\circ}$ were assigned to the 110 and 200 reflections of PE [31]. The intensity of diffraction peaks at $21.6^{\circ}$ and $24.0^{\circ}$ was increased with increasing CNTs content, which suggests the crystallinity of the LLDPE fiber was increased by filled CNTs. The addition of CNTs to the polymer provided a large interface area between the CNTs and polymer, which in turn created very suitable conditions for the nucleation and crystallization process during heating $[2,33]$. Figure 1 (b) shows the XRD pattern of LLDPE treated by the heat drawing process as a function of the CNTs content. Compared to Figure 1(a), the intensities of the diffraction peaks increased greatly with heat drawing process. This is because the crystallinity was increased by orientation of polymer chain of LLDPE fiber due to the heat drawing process. Also, it shows the crystallinity increased with increasing CNTs content $[31,34]$. Figure 2 shows differential scanning calorimetry (DSC) patterns of LLDPE fibers as a function of CNT content. Other studies have demonstrated that the melting temperature of the polymer changed with the addition of CNTs [35]. However, in this study, it can be seen that the melting temperature of both the undrawn and drawn LLDPE fiber was similar. However, comparing Figures 2(a) and 2(b), the melting feature of the drawn LLDPE is broader than that of the undrawn LLDPE. This is because the crystal size became broader with increasing crystallinity of LLDPE fiber by heat drawing process $[2,30,36]$. 


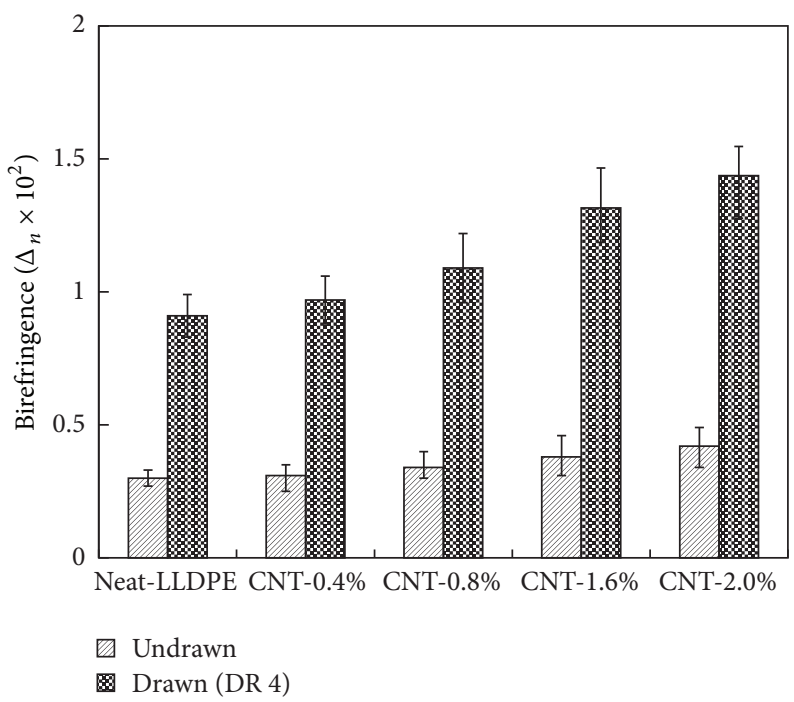

Figure 3: Birefringence $\left(\Delta_{n}\right)$ of undrawn and drawn LLDPE fibers as a function of CNTs content.

TABLE 1: Degree of crystallinity of undrawn and drawn LLDPE fibers as a function of CNTs content.

\begin{tabular}{lcccc}
\hline & Neat-LLDPE & CNT-0.8 wt.\% & CNT-1.6 wt.\% & CNT-2.0 wt.\% \\
\hline Undrawn LLDPE (\%) & 22.58 & 24.76 & 26.32 & 27.91 \\
Drawn LLDPE (DR 4) (\%) & 29.40 & 33.52 & 37.00 & 39.72 \\
\hline
\end{tabular}

Table 1 shows values for the degree of crystallinity calculated using (1) from the melting enthalpy of the DSC patterns of the drawn and undrawn LLDPE fibers. In the case of undrawn LLDPE fibers, when the CNTs content increased to 2.0 wt. $\%$, the crystallinity was increased slightly from $22.58 \%$ to $27.91 \%$. On the other hand, in the case of the drawn LLDPE fibers, when the CNTs content increased to $2.0 \mathrm{wt} . \%$, the crystallinity increased greatly from $29.40 \%$ to $39.72 \%$. As shown in XRD results, heat drawing process is more effective than filled CNTs for increasing the crystallinity [13, 31, 37].

3.2. Degree of Orientation. Figure 3 shows the birefringence $\left(\Delta_{n}\right)$ of undrawn and drawn LLDPE fibers as a function of CNTs content. The $\Delta_{n}$ values of the undrawn LLDPE fiber increased slightly with CNTs content. This shows that although the LLDPE fiber contained anisotropic CNTs, it did not have a great effect on the orientation undrawn LLDPE fiber. However, in the case of the neat-LLDPE, the birefringence increased by about $203.3 \%$, from 0.0030 to 0.0091 , for the undrawn and drawn fibers. It follows that the orientation of polymer chains increased greatly according to the draw ratio (DR) of 4 . In addition, in the case of the LLDPE-CNT 2.0 wt.\% fiber, the increase in the birefringence between the undrawn and drawn fibers was about $242.1 \%$, from 0.0042 to 0.0143 . This was a much larger increase than the neat-LLDPE fiber, which indicates that the anisotropic CNTs are oriented along the polymer chain by heat drawing $[38,39]$.
3.3. Tensile Properties. Figure 4 shows tensile strength for undrawn and drawn LLDPE fibers as a function of CNTs content. As shown in Figures 4(a) and 4(b), the strength at yield and strength at break were increased with increasing the content of CNTs. However, the strength at break of LLDPE fiber decreased at CNTs contents of above $1.6 \mathrm{wt} . \%$. The reason may be due to the agglomeration of CNTs. As shown in Figure 4(a), the strength at yield of the neatLLDPE fiber increased by $419 \%$ from $8.11 \mathrm{MPa}$ to $42.17 \mathrm{MPa}$ by heat drawing process. On the other hand, the strength at yield of 1.6 wt. $\%$ LLDPE-CNT fiber increased by $267 \%$ from 13.94 MPa to 51.18 MPa. The increase of LLDPE-CNTs 1.6 wt.\% fiber is less than that of the neat-LLDPE fiber, suggesting that the strength at yield depends more on the increased orientation of the polymer chains than the CNTs content. However, in the case of the tensile strength at break (Figure 4(b)), the neat-LLDPE fiber increased by $180 \%$ from 16.54 MPa to $46.33 \mathrm{MPa}$, whereas that of the LLDPE-CNTs 1.6 wt.\% fiber increased by $191 \%$ from $22.78 \mathrm{MPa}$ to $66.41 \mathrm{MPa}$ after heat drawing process. Compared to the strength at yield, the tensile strength at break depends on both the CNTs contents and the orientation of the polymer chains. As shown in Figure 4(c), the elongation at break continuously decreased with increasing the CNTs contents. In the case of undrawn LLDPE fiber, the plastic deformation of neat-LLDPE fiber is about twice that of the LLDPE-CNTs 2.0 wt.\% fiber, $410 \%$ and $214 \%$, respectively; it indicates that the elasticity of the 


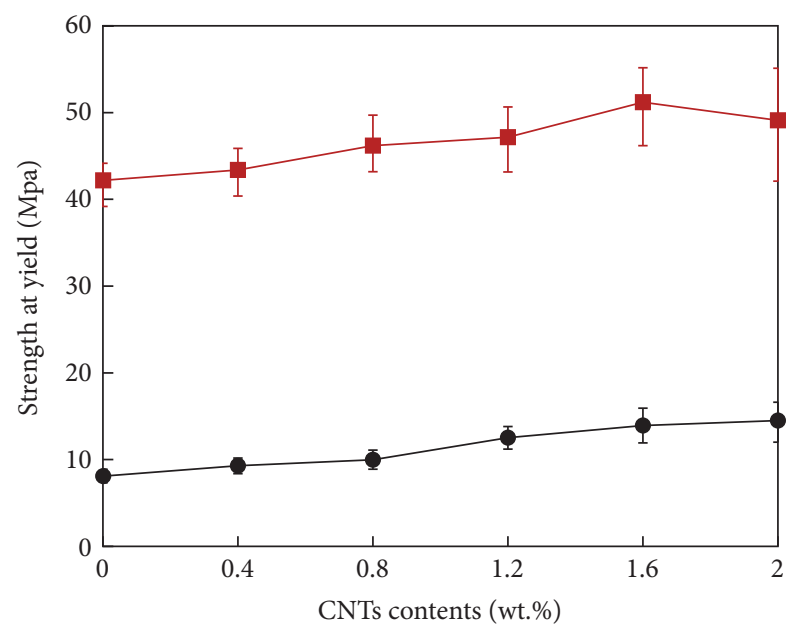

Undrawn fiber Drawn fiber (DR 4)

(a)

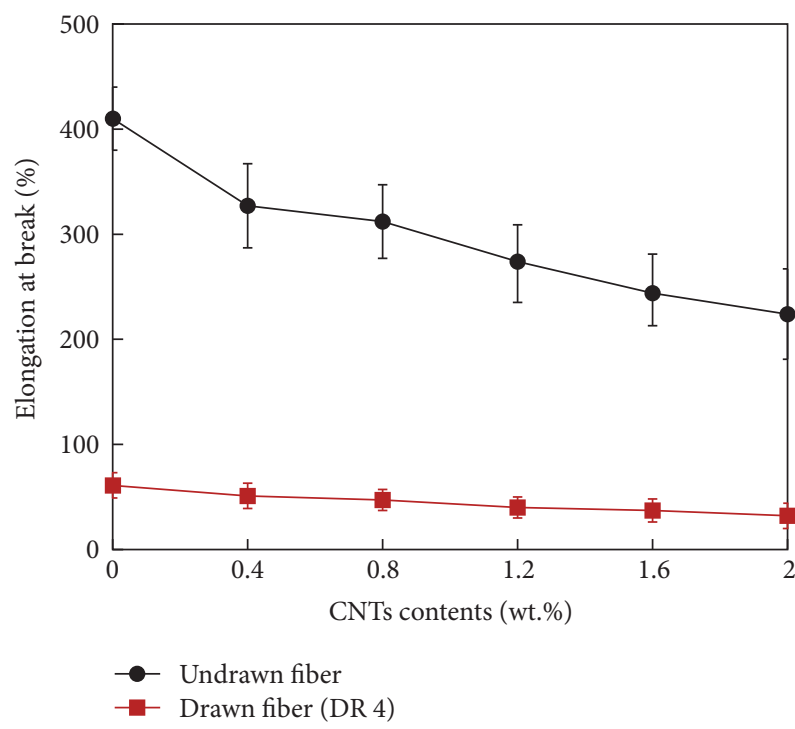

(c)

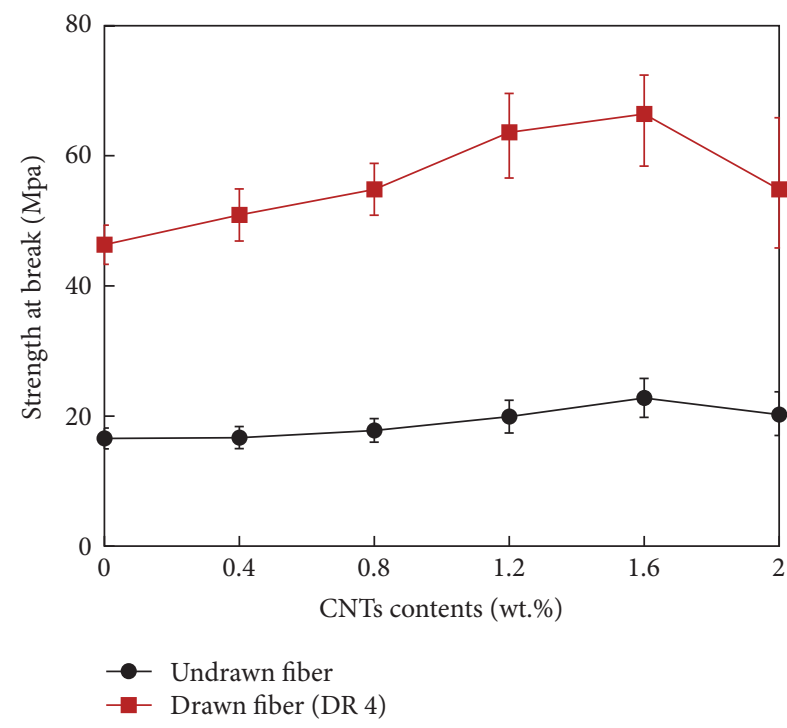

(b)

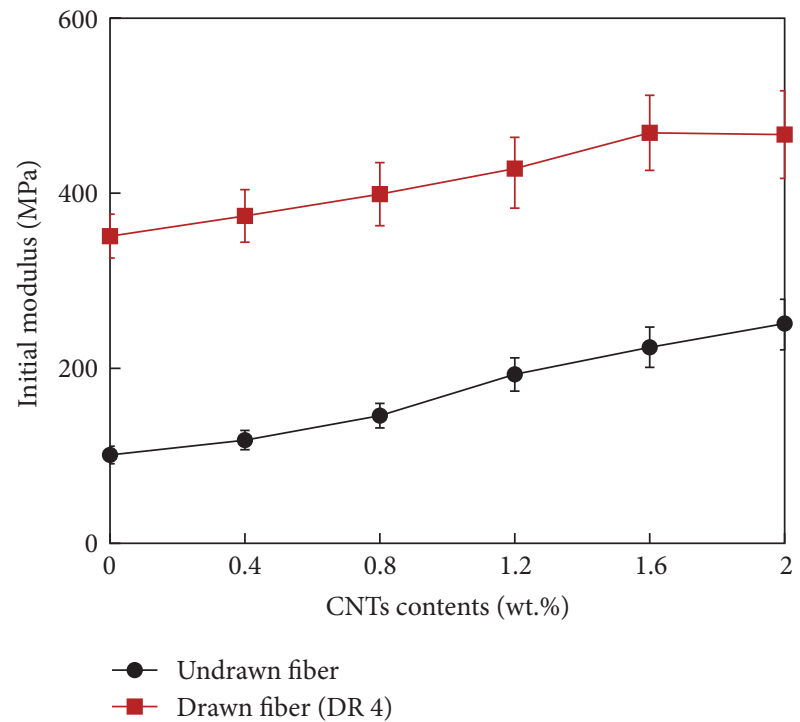

(d)

FIGURE 4: Tensile property of undrawn and drawn LLDPE fiber as a function of CNTs contents: (a) strength at yield; (b) strength at break; (c) elongation at break; and (d) initial modulus.

CNT results in decreased plastic deformation of the LLDPE fiber. Also, after heat drawing process, the plastic deformation of the LLDPE fiber decreased rapidly. Comparing the values of the undrawn and drawn fibers, the neat-LLDPE fiber decreased from $410 \%$ to $61 \%$, and the LLDPE-CNTs $2.0 \mathrm{wt} . \%$ fiber decreased significantly from $214 \%$ to $32 \%$. Hence, these results show that the heat drawing process is very effective in decreasing the plastic deformation of LLDPE fibers. As shown in Figure 4(d), the initial modulus increased continuously with increasing CNTs contents. This means that the increase in the crystallinity of the LLDPE fiber made the LLDPE fiber stiffer. Therefore, the heat drawing process increases the motility of the macromolecular chains and leads them to better rearrangement in the fiber axis direction. In other words, the heat drawing process results in straightening and sliding of the strained interfibrillar tie molecules, which allow easy alignment of the polymer segments to the crystals $[40,41]$. This can be confirmed by an increase in crystallinity.

3.4. Electrical Conductivity. Figure 5 shows the electrical conductivity $(\sigma)$ of undrawn and drawn LLDPE fiber as a function of CNT content compared to tensile strength. The electrical conductivity of the drawn neat-LLDPE fiber was higher than that of the undrawn neat-LLDPE fiber. This is because the measuring range of the electrical resistivity meter 


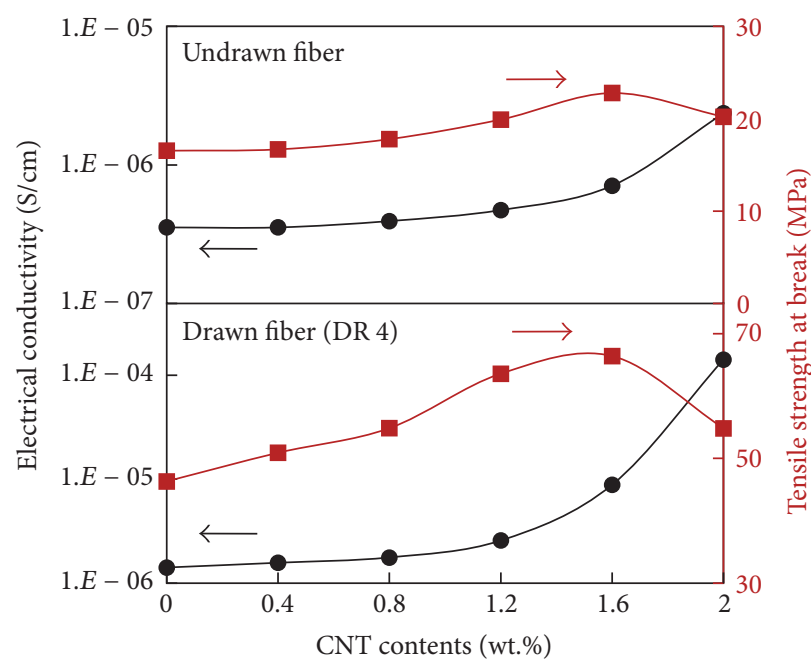

FIGURE 5: Electrical conductivity $(\sigma)$ and tensile strength of undrawn and drawn LLDPE fiber as a function of CNTs content for a draw ratio of 4 .

is only up to $10^{12} \Omega$. Although the electric resistances of the drawn and undrawn fibers were the same as $10^{12} \Omega$, the cross-section area of the drawn LLDPE fiber is smaller than that of the undrawn LLDPE fiber. The electrical conductivity increased greatly with increasing CNTs content. The increase of electrical conductivity started to increase from the decrease of tensile strength of undrawn and drawn LLDPE fiber. This is due to the agglomeration of CNTs and formation of a network with increasing content of CNTs. Also, in the same CNT content, the electrical conductivity of drawn LLDPE fiber was higher than that of undrawn LLDPE fiber. This is considered that the CNTs were networked by heat drawing process due to anisotropic CNTs aggregation and orientation in the axial direction and decrease of the diameter of LLDPE fiber [4244].

3.5. SEM and TEM. Figure 6 shows cross-sectional SEM and TEM images of undrawn and drawn LLDPE fibers with CNTs $1.6 \mathrm{wt} . \%$ and $2.0 \mathrm{wt} . \%$. As shown in energy dispersive spectroscopy (EDS) (Figures $6\left(a_{3}\right), 6\left(b_{3}\right)$, and $6\left(c_{3}\right)$ ), the spot is CNT. It can be seen that the distance between the CNTs inside LLDPE fiber is shorter after heat drawing with a draw ratio of four as shown in Figures $6\left(a_{2}\right)$ and $6\left(b_{2}\right)$. The materials which were formed of fiber were shrunk in the center axis direction by heat drawing process and drawn in the axial direction. Therefore, the filled CNTs were aggregated and oriented with each other. The aggregation of CNTs can be seen in the LLDPE fiber in the Figure $6\left(c_{4}\right)$.

\section{Conclusions}

In this study, thin LLDPE fiber was manufactured with dryjet wet spinning. To decrease plastic deformation and increase tensile strength, CNT was filled and heat drawing process was applied. The following conclusions were drawn. (i) As the CNTs content increased to $2.0 \mathrm{wt} . \%$, the crystallinity of undrawn LLDPE fiber was increased, but that of drawn LLDPE fiber was increased greatly. The value of the birefringence for the heat drawn LLDPE fiber was significantly higher than that of the undrawn LLDPE fiber.

(ii) The strength at yield and strength at break of LLDPE fibers increased with CNTs concentration up to 1.6 wt.\% and then decreased. The initial modulus increased with increasing CNT content, but the elongation at break decreased continuously with increasing CNTs contents.

(iii) The electrical conductivity of both the undrawn and drawn LLDPE fibers increased with increasing CNTs content. In the same CNTs content, electrical conductivity of drawn LLDPE fibers is higher than that of undrawn LLDPE fiber.

(iv) The heat drawing process increased the crystallinity and the orientation of the polymer chain, and the filling of CNT further increased the crystallinity. As a result, thin LLDPE fibers with high tensile strength and low plastic deformation were manufactured, which can be applied to the textile field based on the characteristics of good softness compared to other high strength olefin fibers.

\section{Disclosure}

Current affiliation of Jong Won Kim is as follows: School of Chemical \& Biomolecular Engineering, Georgia Institute of Technology, Atlanta, GA 30332, USA.

\section{Conflicts of Interest}

The authors declare no conflicts of interest. 

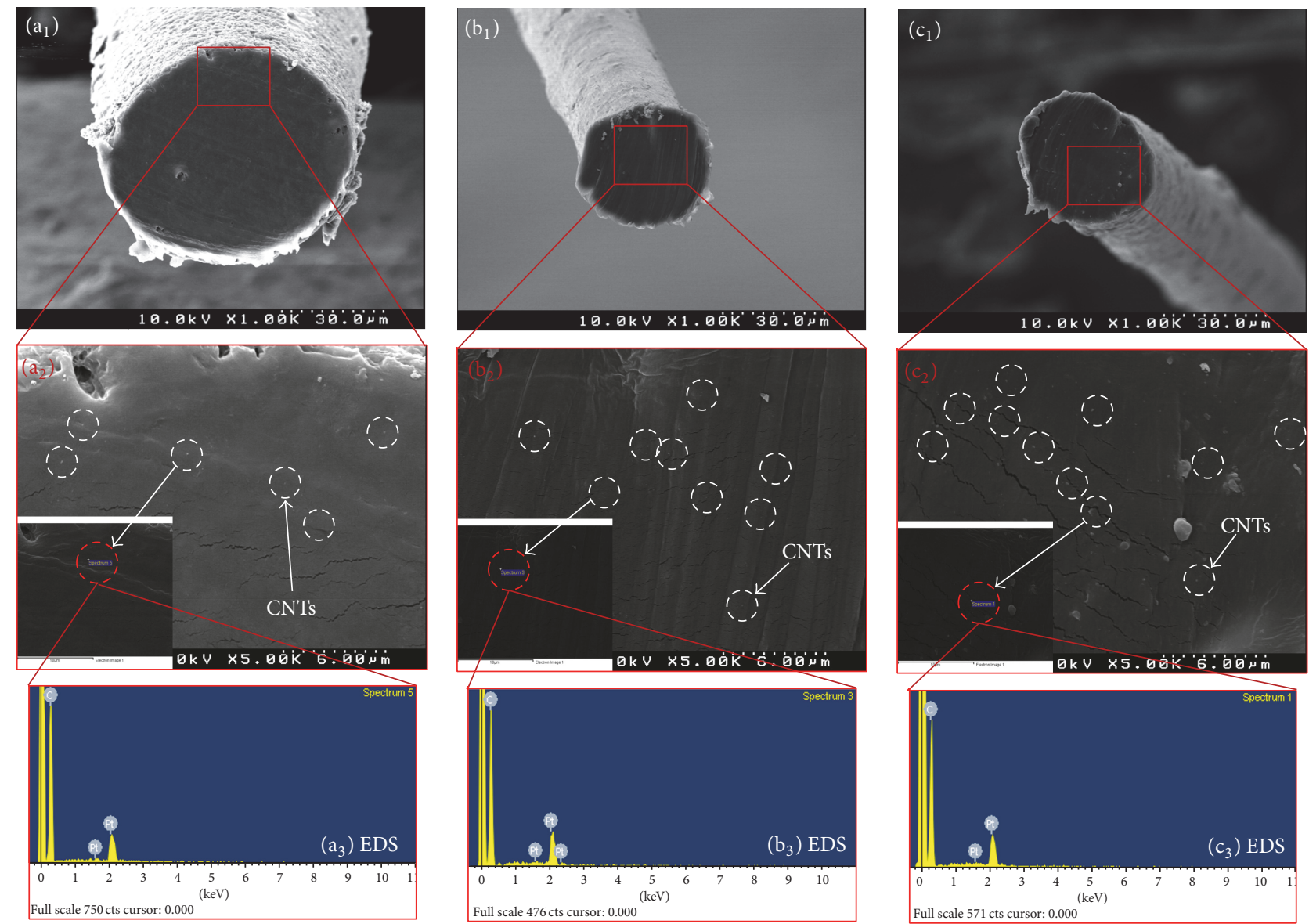

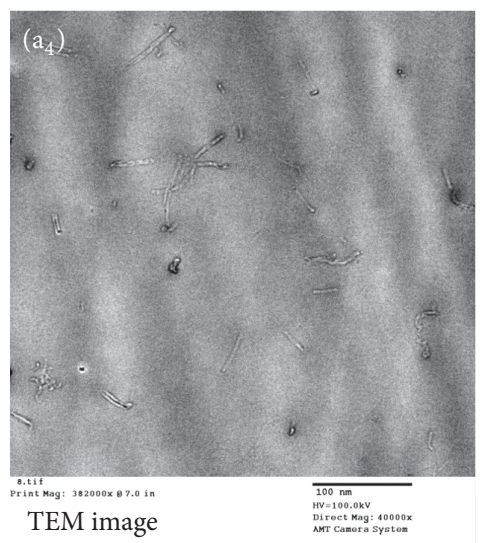

(a) Undrawn fiber (CNT 1.6\%)

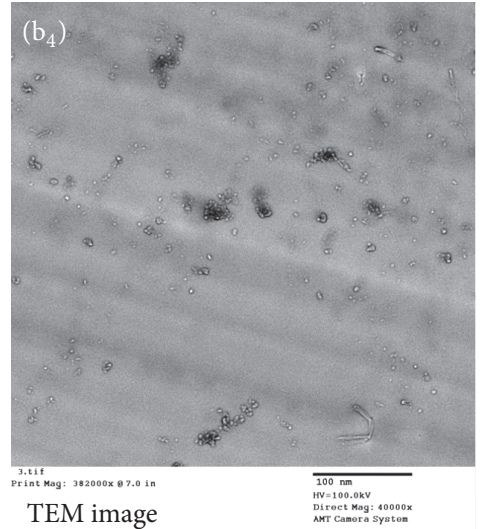

(b) Drawn fiber (CNT 1.6\%)

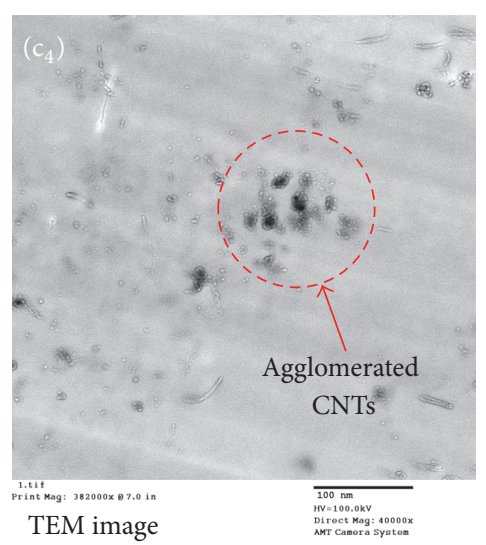

(c) Drawn fiber (CNT 2\%)

FIGURE 6: Cross-sectional SEM and TEM images of undrawn and drawn LLDPE fibers with CNTs 1.6 wt.\% and 2.0 wt.\%: (a) undrawn LLDPECNT 1.6 wt.\%; (b) drawn LLDPE-CNT 1.6 wt.\%; (c) drawn LLDPE-CNT 2.0 wt.\%.

\section{References}

[1] X. Huang, Q. Ke, C. Kim et al., "Nonisothermal crystallization behavior and nucleation of LDPE/Al nano- and microcomposites," Polymer Engineering and Science, vol. 47, no. 7, pp. 10521061, 2007.

[2] P. N. Khanam and M. A. A. Almaadeed, "Processing and characterization of polyethylene-based composites," Advanced
Manufacturing: Polymer \& Composites Science, vol. 1, no. 2, pp. 63-79, 2015.

[3] J.-Z. Liang, "Tensile, flow, and thermal properties of CaCO3filled LDPE/LLDPE composites," Journal of Applied Polymer Science, vol. 104, no. 3, pp. 1692-1696, 2007.

[4] L. Qiu, W. Chen, and B. Qu, "Morphology and thermal stabilization mechanism of LLDPE/MMT and LLDPE/LDH nanocomposites," Polymer, vol. 47, no. 3, pp. 922-930, 2006. 
[5] S. L. Gessner, J. D. Gillespie, J. A. Austin, D. D. Newkirk, and W. Fowells, "Nonwoven fabrics and fabric laminates from multiconstituent polyolefin fiber," U. S. Patent, no. 6,465,378, Oct. 2002.

[6] K. Masuda, Y. Kawakami, and H. Morimoto, "Fibers, nonwoven fabric and uses thereof," U. S. Patent, no. 9,074,303, Jul. 2015.

[7] J. A. Lu, R. H. Turner, L. M. Reynolds et al., "Laminates with bonded webs," U. S. Patent, no. 8,728,051, May, 2014.

[8] T. E. Quantrille, H. E. Thomas, B. D. Meece et al., "Extensible composite nonwoven fabrics," U. S. Patent, no. 6,506,698, Jan. 2003.

[9] R. Pérez, E. Rojo, M. Fernández, V. Leal, P. Lafuente, and A. Santamaría, "Basic and applied rheology of m-LLDPE/LDPE blends: Miscibility and processing features," Polymer, vol. 46, no. 19, pp. 8045-8053, 2005.

[10] K. Mezghani, M. Farooqui, S. Furquan, and M. Atieh, "Influence of carbon nanotube (CNT) on the mechanical properties of LLDPE/CNT nanocomposite fibers," Materials Letters, vol. 65, no. 23-24, pp. 3633-3635, 2011.

[11] H. Mahfuz, A. Adnan, V. K. Rangari, S. Jeelani, and B. Z. Jang, "Carbon nanoparticles/whiskers reinforced composites and their tensile response," Composites Part A: Applied Science and Manufacturing, vol. 35, no. 5, pp. 519-527, 2004.

[12] J. W. Kim and J. S. Lee, "Preparation of carbon fibers from linear low density polyethylene," Carbon, vol. 94, pp. 524-530, 2015.

[13] A. Sarı, "Form-stable paraffin/high density polyethylene composites as solid-liquid phase change material for thermal energy storage: preparation and thermal properties," Energy Conversion and Management, vol. 45, no. 13-14, pp. 2033-2042, 2004.

[14] T. K. Dey and M. Tripathi, "Thermal properties of silicon powder filled high-density polyethylene composites," Thermochimica Acta, vol. 502, no. 1-2, pp. 35-42, 2010.

[15] L. Fang, Y. Leng, and P. Gao, "Processing of hydroxyapatite reinforced ultrahigh molecular weight polyethylene for biomedical applications," Biomaterials, vol. 26, no. 17, pp. 3471-3478, 2005.

[16] Q. Zhang, S. Rastogi, D. Chen, D. Lippits, and P. J. Lemstra, "Low percolation threshold in single-walled carbon nanotube/high density polyethylene composites prepared by melt processing technique," Carbon, vol. 44, no. 4, pp. 778-785, 2006.

[17] R. K. Kaul, A. F. Barghouty, and H. M. Dahche, "Space radiation transport properties of polyethylene-based composites," Annals of the New York Academy of Sciences, vol. 1027, pp. 138-149, 2004.

[18] S. L. Ruan, P. Gao, X. G. Yang, and T. X. Yu, “Toughening high performance ultrahigh molecular weight polyethylene using multiwalled carbon nanotubes," Polymer, vol. 44, no. 19, pp. 5643-5654, 2003.

[19] S. H. Abbasi, A. A. Al-Juhani, A. Ul-Hamid, and I. A. Hussein, "Effect of aspect ratio, surface modification and compatibilizer on the mechanical and thermal properties of LDPE-MWCNT nanocomposites," Polymers, vol. 67, Article ID 067, pp. 1-17, 2011.

[20] M.-F. Yu, B. S. Files, S. Arepalli, and R. S. Ruoff, “Tensile loading of ropes of single wall carbon nanotubes and their mechanical properties," Physical Review Letters, vol. 84, no. 24, pp. 55525555, 2000.

[21] E. W. Wong, P. E. Sheehan, and C. M. Lieber, "Nanobeam mechanics: elasticity, strength, and toughness of nanorods and nanotubes," Science, vol. 277, no. 5334, pp. 1971-1975, 1997.

[22] Y. Bin, A. Yamanaka, Q. Chen, Y. Xi, X. Jiang, and M. Matsuo, "Morphological, electrical and mechanical properties of ultrahigh molecular weight polyethylene and multi-wall carbon nanotube composites prepared in decalin and paraffin," Polymer Journal, vol. 39, no. 6, pp. 598-609, 2007.
[23] A. Mierczynska, M. Mayne-L'Hermite, G. Boiteux, and J. K. Jeszka, "Electrical and mechanical properties of carbon nanotube/ultrahigh-molecular-weight polyethylene composites prepared by a filler prelocalization method," Journal of Applied Polymer Science, vol. 105, no. 1, pp. 158-168, 2007.

[24] Q. Zhang, D. R. Lippits, and S. Rastogi, "Dispersion and rheological aspects of SWNTs in ultrahigh molecular weight polyethylene," Macromolecules, vol. 39, no. 2, pp. 658-666, 2006.

[25] J.-T. Yeh, Y.-C. Lai, H. Liu et al., "Ultradrawing properties of ultrahigh- molecular-weight polyethylene/carbon nanotube fibers prepared at various formation temperatures," Polymer International, vol. 60, no. 1, pp. 59-68, 2011.

[26] Y. Zou, Y. Feng, L. Wang, and X. Liu, "Processing and properties of MWNT/HDPE composites," Carbon, vol. 42, no. 2, pp. 271277, 2004.

[27] R. Haggenmueller, J. E. Fischer, and K. I. Winey, "Single wall carbon nanotube/polyethylene nanocomposites: Nucleating and templating polyethylene crystallites," Macromolecules, vol. 39, no. 8, pp. 2964-2971, 2006.

[28] K. Q. Xiao, L. C. Zhang, and I. Zarudi, "Mechanical and rheological properties of carbon nanotube-reinforced polyethylene composites," Composites Science and Technology, vol. 67, no. 2, pp. 177-182, 2007.

[29] W. Tang, M. H. Santare, and S. G. Advani, "Melt processing and mechanical property characterization of multi-walled carbon nanotube/high density polyethylene (MWNT/HDPE) composite films," Carbon, vol. 41, no. 14, pp. 2779-2785, 2003.

[30] J. Aalaie, A. Rahmatpour, and S. Maghami, "Preparation and characterization of linear low density polyethylene/carbon nanotube nanocomposites," Journal of Macromolecular Science Part B: Physics, vol. 46, no. 5, pp. 877-889, 2007.

[31] H. Mahfuz, A. Adnan, V. K. Rangari, and S. Jeelani, "Manufacturing and characterization of carbon nanotube/polyethylene composites," International Journal of Nanoscience, vol. 4, no. 1, pp. 55-72, 2005.

[32] B. Wunderlich, Macromolecular Physics, Academic Press, New York, NY, USA, 1976.

[33] T. McNally, P. Pötschke, P. Halley et al., "Polyethylene multiwalled carbon nanotube composites," Polymer, vol. 46, no. 19, pp. 8222-8232, 2005.

[34] K. P. Ryan, S. M. Lipson, A. Drury et al., "Carbon-nanotube nucleated crystallinity in a conjugated polymer based composite," Chemical Physics Letters, vol. 391, no. 4-6, pp. 329-333, 2004.

[35] S. Kanagaraj, F. R. Varanda, T. V. Zhil'tsova, M. S. A. Oliveira, and J. A. O. Simões, "Mechanical properties of high density polyethylene/carbon nanotube composites," Composites Science and Technology, vol. 67, no. 15-16, pp. 3071-3077, 2007.

[36] L. Valentini, J. Biagiotti, J. M. Kenny, and S. Santucci, "Morphological characterization of single-walled carbon nanotubes-PP composites," Composites Science and Technology, vol. 63, no. 8, pp. 1149-1153, 2003.

[37] D. Milicevic, M. Micic, G. Stamboliev, A. Leskovac, M. Mitric, and E. Suljovrujic, "Microstructure and crystallinity of polyolefins oriented via solid-state stretching at an elevated temperature," Fibers and Polymers, vol. 13, no. 4, pp. 466-470, 2012.

[38] G. Terife and K. A. Narh, "Properties of carbon nanotube reinforced linear low density polyethylene nanocomposites fabricated by cryogenic ball-milling," Polymer Composites, vol. 32, no. 12, pp. 2101-2109, 2011.

[39] P. Pötschke, H. Brünig, A. Janke, D. Fischer, and D. Jehnichen, "Orientation of multiwalled carbon nanotubes in composites 
with polycarbonate by melt spinning," Polymer, vol. 46, no. 23, pp. 10355-10363, 2005.

[40] J. Dong, C. Yin, J. Lin, D. Zhang, and Q. Zhang, "Evolution of the microstructure and morphology of polyimide fibers during heat-drawing process," RSC Advances, vol. 4, no. 84, pp. 4466644673, 2014.

[41] A. Rudolf, J. Geršak, and M. S. Smole, "The effect of heat treatment conditions using the drawing process on the properties of PET filament sewing thread," Textile Research Journal, vol. 82, no. 2, pp. 161-171, 2012.

[42] J. Shen, M. F. Champagne, R. Gendron, and S. Guo, "The development of conductive carbon nanotube network in polypropylene-based composites during simultaneous biaxial stretching," European Polymer Journal, vol. 48, no. 5, pp. 930-939, 2012.

[43] M. Park, H. Kim, and J. P. Youngblood, "Strain-dependent electrical resistance of multi-walled carbon nanotube/polymer composite films," Nanotechnology, vol. 19, no. 5, Article ID 055705, 2008.

[44] H. Deng, R. Zhang, C. T. Reynolds, E. Bilotti, and T. Peijs, "A novel concept for highly oriented carbon nanotube composite tapes or fibres with high strength and electrical conductivity," Macromolecular Materials and Engineering, vol. 294, no. 11, pp. 749-755, 2009. 

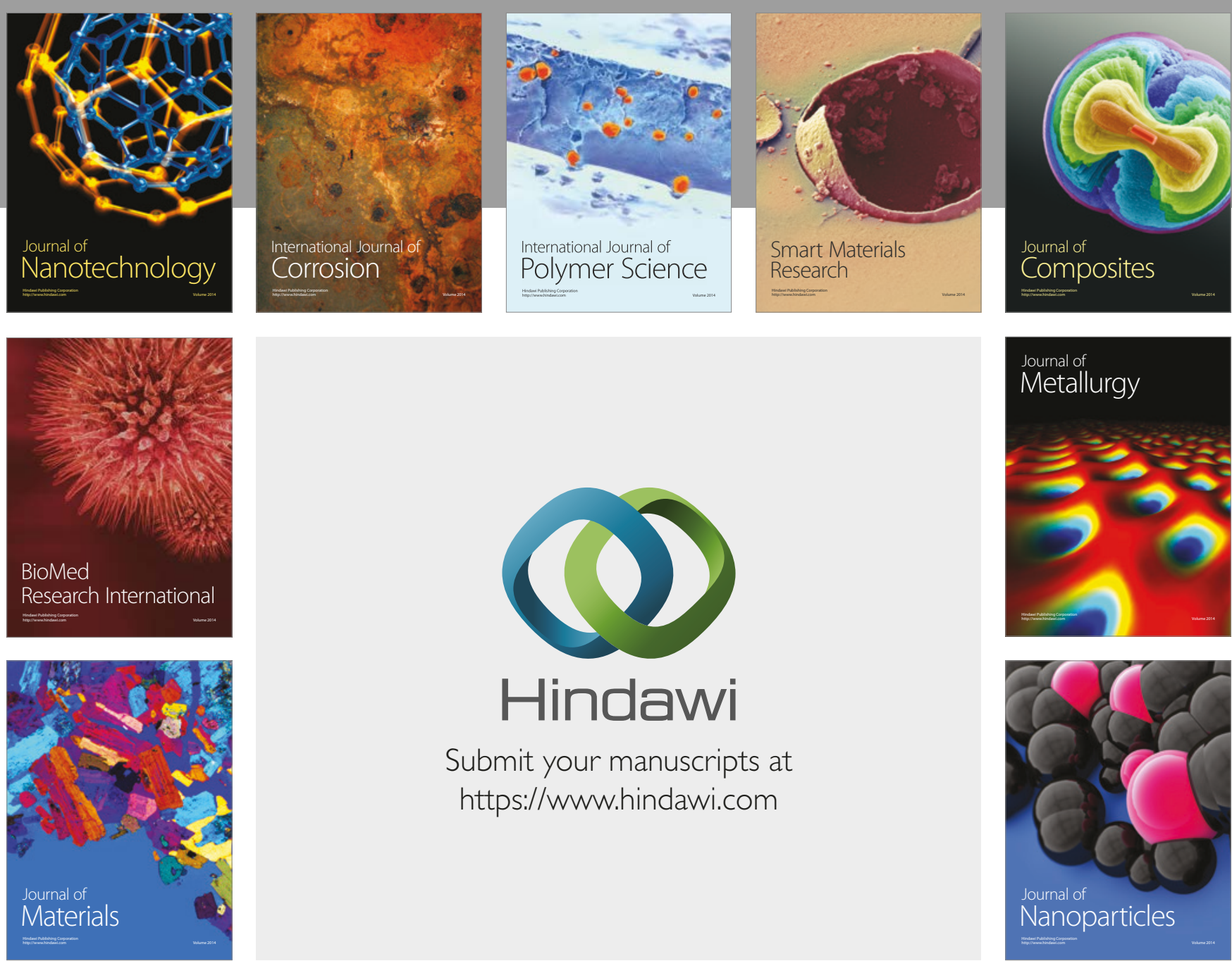

\section{Hindawi}

Submit your manuscripts at

https://www.hindawi.com
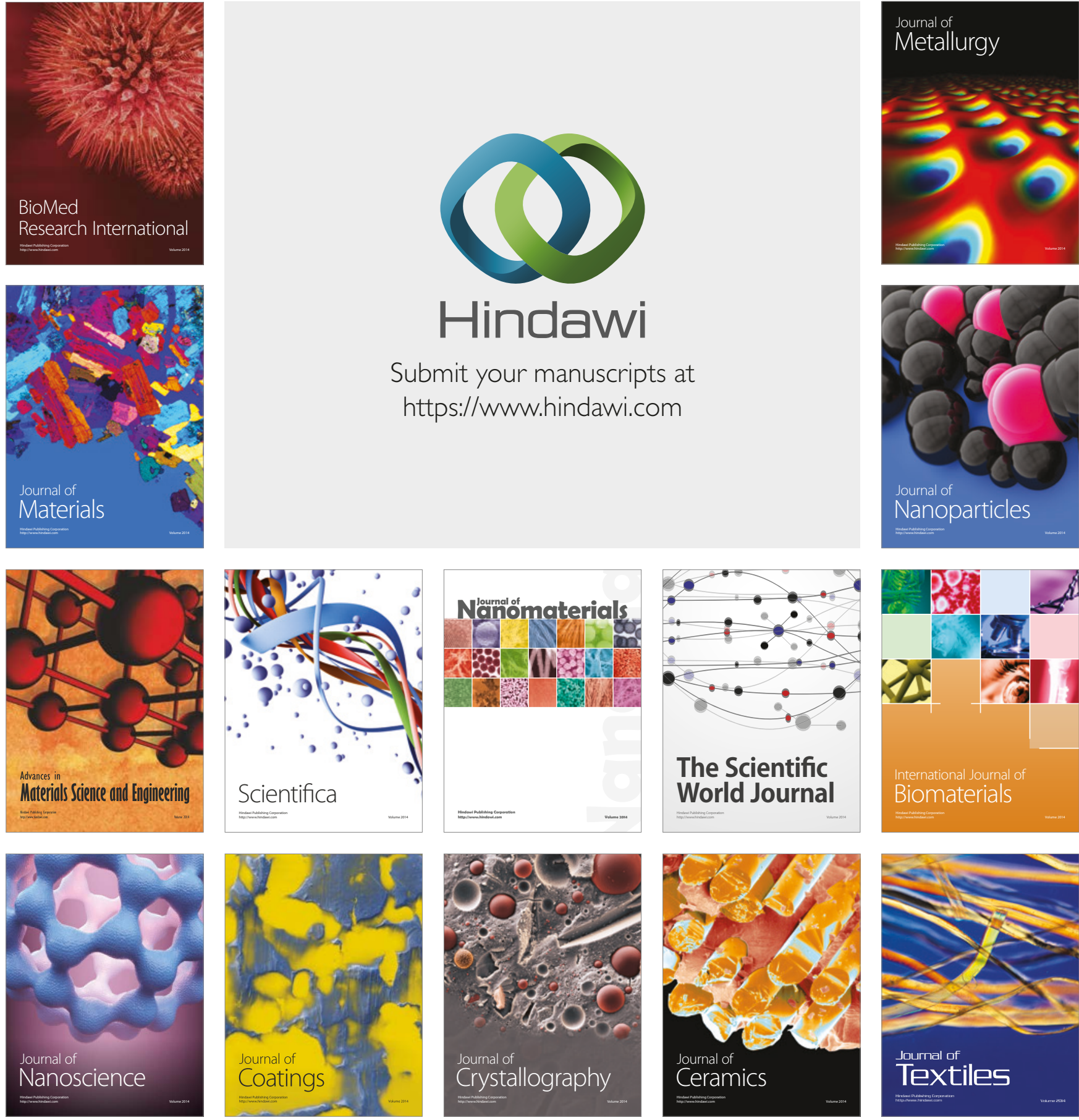

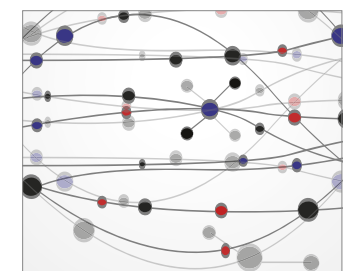

The Scientific World Journal
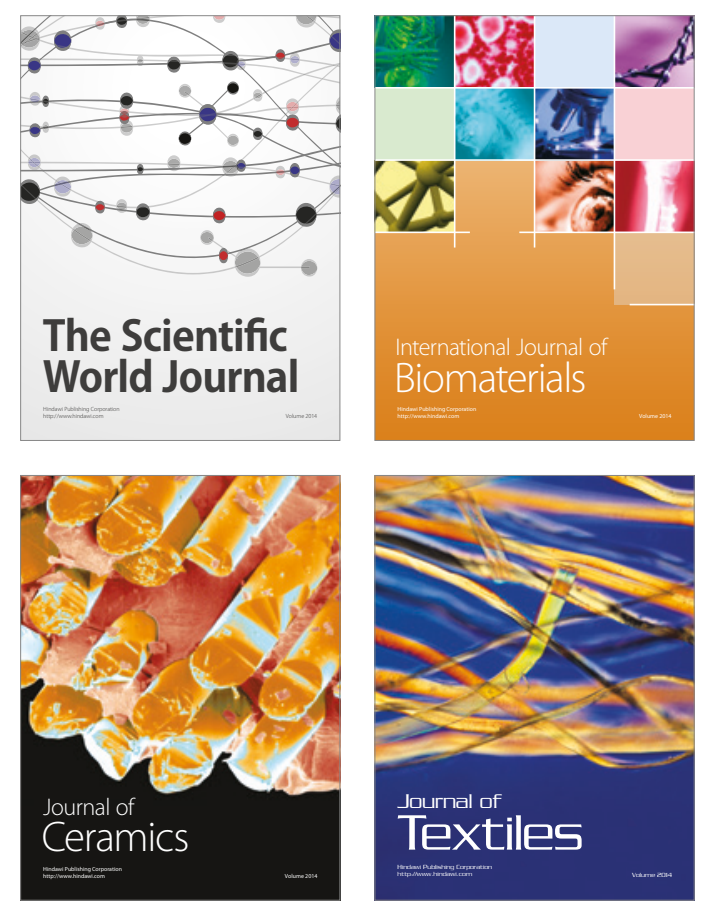